\title{
Breve estado da arte da Web 2.0 no Ensino de Química: análise das produções em periódicos e congressos científicos
}

\author{
Brief State of the Art of Web 2.0 in the Chemistry Teaching: analysis of the productions in \\ Scientifics journals and proceedings
}

\author{
Bruno Silva Leite \\ Universidade Federal Rural de Pernambuco \\ leitebrunosilva@gmail.com
}

\begin{abstract}
Resumo
Esta pesquisa teve como objetivo realizar um levantamento e uma análise sobre o estado da arte de ferramentas da Web 2.0 no Ensino de Química desde o surgimento da Web 2.0, em 2005, até o ano de 2015. Analisamos a produção de 6061 artigos/comunicações em quatro periódicos e quatro congressos científicos. Foram encontrados 122 trabalhos sobre Web Social nos periódicos e 217 nos congressos científicos, de um total de 1971 publicações delimitadas pelas TIC, com 103 trabalhos direcionados exclusivamente ao Ensino de Química. Além disso, apresenta-se a utilização de alguns recursos da Web 2.0 e como estes estão sendo inseridos no Ensino de Química, destacando um breve resumo de trabalhos divulgados. Embora as publicações na área não sejam homogêneas, os resultados mostram um pequeno crescimento das pesquisas utilizando a Web 2.0 no Ensino de Química no seu primeiro decênio. Este artigo, além de apresentar um panorama geral sobre ferramentas da Web 2.0 no Ensino de Química, serve de base para a ampliação das pesquisas na área e no desenvolvimento de novos estudos.
\end{abstract}

Palavras-Chave: Web 2.0; TIC; Estado da arte; Ensino de Química.

\begin{abstract}
This research aimed to carry out a survey and analysis of the state of the art of the Web 2.0 tools in Chemistry Teaching since the appearance of Web 2.0 in 2005 until the year 2015. We analyzed the production of 6061 articles/communications in four scientific journals and four scientific proceedings. We found 122 papers on Social Web in journals and 217 in scientific proceedings, of a total of 1971 publications delimited by ICT, with 103 publications exclusively devoted to chemistry teaching. In addition, it presents the use of some Web 2.0 resources and how these are being inserted in the chemistry teaching, highlighting a brief summary of published articles. Despite the publications in the area are not homogeneous, the results show a small growth in research using Web 2.0 in chemistry teaching in its first decade. This article, in addition to presenting an overview of Web 2.0 tools in chemistry teaching, serves as the basis for the expansion of research in the area and in the development of new studies.
\end{abstract}

Keywords: Web 2.0; ICT; State of the art; Chemistry Teaching.

Cite as: Leite, B. S. (2019). Brief State of the Art of Web 2.0 in the Chemistry Teaching: analysis of the productions in Scientifics journals and proceedings (Breve estado da arte da Web 2.0 no Ensino de Química: análise das produções em periódicos e congressos científicos). Brazilian Journal of Computers in Education (Revista Brasileira de Informática na Educação - RBIE), 27(3), 265-284. DOI: 10.5753/RBIE.2019.27.03.265 


\section{Introdução}

A produção acadêmica e a divulgação dos resultados de pesquisas têm proporcionado uma grande contribuição na construção do conhecimento individual e coletivo, e esses resultados são um dos principais objetivos da ciência (Dias, Neto, \& Cunha, 2011). A pesquisa acadêmica não é um processo isolado, mas construído colaborativamente através da comunidade acadêmica (Ribeiro, 2015), em que, a cada nova investigação realizada, aprendemos, contestamos, criticamos e complementamos essas produções.

Nesse sentido, a produção científica de uma área de conhecimento reflete o seu estado da arte e sua evolução (Borba, Poeta, \& Vicente, 2011). O estado da arte é uma das partes mais importantes de todo trabalho científico, uma vez que faz referência ao que já se tem descoberto sobre o assunto pesquisado, evitando que se perca tempo com investigações desnecessárias (Marques, 2004). Ademais, ele contribui para o desenvolvimento de modelos, conceitos e novos postulados. É uma atividade complexa por se tratar de uma reflexão crítica. No estado da arte, devemos iniciar um processo de coleta de dados refletindo sobre eles, relacionando-os com o tema em discussão, interagindo com o autor, elaborando um escrito, com boa argumentação e conclusões adquiridas pela reflexão realizada.

Definida como de caráter bibliográfico (Ferreira, 2002), o estado da arte apresenta o desafio de mapear e de discutir sobre uma certa produção acadêmica em diferentes campos do conhecimento. É considerado um método de pesquisa que se realiza por meio de uma revisão bibliográfica sobre a produção de determinada temática em uma área de conhecimento específica. Para Ferreira (2002), o estado da arte tenta responder quais características e dimensões vêm sendo destacadas e amplamente discutidas em diferentes épocas e lugares, de que formas e em que condições têm sido produzidas certas publicações acadêmicas. Consideramos que o uso das tecnologias pode conduzir a uma compreensão adequada dos caminhos metodológicos que estão sendo tomados pela comunidade científica. É nesse contexto que as tecnologias têm dado grandes contribuições em pesquisas do estado da arte.

As conhecidas Tecnologias da Informação e Comunicação (TIC) são e serão elementos essenciais nos espaços de formação e interação entre os indivíduos. Elas podem gerar inúmeros ganhos potenciais, já que permitem criar novas formas de relacionar-se, em que as barreiras de tempo e espaço são eliminadas, gerando processos de análises e reflexão em torno de suas próprias características. A presença das TIC, assim como das mídias e linguagens a elas associadas, se torna cada vez mais intensa em todos os setores sociais, em especial, no campo educacional (Martinhão, 2016). Percebe-se que a cada dia as tecnologias são incorporadas ao processo pedagógico como recursos didáticos. Infelizmente esta utilização não está sendo acompanhada de um processo amplo de discussão dos aspectos teóricos e práticos envolvidos (Leite, 2014).

Além da necessária discussão teórica na utilização das TIC, pesquisas e processos cuidadosos de elaboração de materiais educacionais que utilizem estas tecnologias ainda estão longe de serem satisfatórios. Segundo Leão (2011), citado por Leite e Leão (2015, p. 289), “a utilização das TIC, dentre elas a Internet em especial, vem se apresentando como ferramenta bastante acionada na construção do conhecimento". Neste sentido, é fundamental a adequação da escola, dos professores e dos alunos ao bom uso da internet. Hoje dispomos de diversos recursos tecnológicos que proporcionam e aportam a Era da informação. As tecnologias evoluem com muita rapidez. Diariamente surgem novos processos e produtos diferenciados e mais sofisticados: smartphones, tablets, softwares, vídeos, computador multimídia, Internet, televisão interativa, videogames etc. Para que as TIC possam trazer alterações no processo educativo, no entanto, elas precisam ser compreendidas e incorporadas pedagogicamente.

As TIC exigem uma formação permanente do cidadão para se desenvolver tanto pessoal como profissionalmente ao longo de toda sua vida. Em 2005 presenciamos o surgimento de um novo 
termo na rede mundial de computadores, a Web 2.0. Esse termo, que faz um trocadilho com o tipo de notação em informática que indica a versão de um software, é considerado a segunda geração de serviços online e se caracteriza por potencializar as formas de publicação, compartilhamento e organização de informações, além de ampliar os espaços para a interação entre os participantes do processo. O termo foi proposto por Tim O’Reilly (O’Reilly, 2005), que observava um momento crucial na evolução da Internet que causava a enorme popularidade de uma nova geração de páginas web, como por exemplo MySpace, Youtube, Blogger e Flickr (Clercq, 2009).

De acordo com Leite (2014, p. 60), a "Web 2.0 se refere não apenas a uma combinação de técnicas informáticas, mas também a um determinado período tecnológico, a um conjunto de novas estratégias mercadológicas e a processos de comunicação mediados pelo computador”. Ela designa uma segunda geração de comunidades e serviços baseados na plataforma Web. Embora o termo tenha uma conotação de uma nova versão para a Web, ele não refere a atualização nas suas especificações técnicas, mas a uma mudança na forma como ela é encarada por usuários e desenvolvedores. As ferramentas da Web 2.0 contribuem para que seus usuários compartilhem e construam "conhecimento" de forma simples, colaborativa e interativa (Isotani, Mizoguchi, Bittencourt, \& Costa, 2009). Uma definição clara e compacta da Web 2.0 mostra-se bastante difícil, não somente porque há falta de consenso acerca da relevância e pertinência do termo, mas também porque se usa a palavra "Web 2.0" para indicar uma das mudanças que sucedem simultaneamente o âmbito tecnológico, social e empresarial (Clercq, 2009).

Pesquisas sobre a Web 2.0, por exemplo, retratam como estudantes se apropriam de suas ferramentas (Oliveira \& Dutra, 2014); como são utilizadas no ambiente virtual de bibliotecas universitárias (Azevedo \& Almeida, 2011; Brito \& Silva, 2010); seu uso em periódicos científicos (Neubert, Rodrigues, \& Fachin, 2016); como são investigados os fatores que predizem as intenções dos professores no uso das ferramentas da Web 2.0 em suas salas de aula (Sadaf, Newby, \& Ertmer, 2016); suas aplicações na Educação (Isotani et al., 2009) e no Ensino de Química (Leite, 2014). Nesse contexto, a Web 2.0 propicia maior interatividade, tornando o ambiente presencial e virtual mais dinâmico, e os educadores da atualidade não podem deixar de utilizar tais recursos, uma vez que impacta no aprendizado dos usuários, proporcionando o desenvolvimento de habilidades e competências na utilização de recursos digitais, através da interatividade entre os seus participantes.

A proposta apresentada neste trabalho constitui-se em um acervo de pesquisas pautadas na Web 2.0 (ou Web Social) e no estudo sobre como está sendo inserida no ensino das ciências, em especial da Química. A inclusão destes recursos deve ser encarada como uma melhoria no processo educacional aliado às práticas pedagógicas do ensino de ciências. O conteúdo deste artigo apresenta um breve estado da arte das publicações sobre as ferramentas da Web 2.0 no Ensino de Química. Este estudo também se justifica por entender que mapear e conhecer trabalhos acadêmicos publicados em periódicos e congressos, sobre as ferramentas da Web 2.0, por meio de uma revisão da literatura, é uma das maneiras de possibilitar a avaliação e a reflexão sobre o uso dessas ferramentas.

O nosso objetivo é evidenciar a evolução da Pesquisa sobre a Web 2.0 no Ensino de Química, ao longo de uma década (2005-2015), no que respeita às suas principais abordagens e, de modo particular, às principais contribuições que demarcam sua ascensão ao longo da década considerada. A pesquisa conduzida é um estudo meta-interpretativo baseado na análise de conteúdo dos artigos/comunicações sobre a Web 2.0, publicados em revistas e eventos científicos, sendo as seguintes as questões de pesquisa:

Como evoluíram as pesquisas sobre a Web 2.0 durante seu primeiro decênio (2005-2015)? Em particular, como foi abordada no Ensino de Química? Quais as orientações da pesquisa (análises das ferramentas; aplicações e uso das ferramentas; perspectivas a partir de discussões 
teóricas sobre as ferramentas da Web 2.0) evidenciadas nos artigos/comunicações analisados? Quais as principais conclusões, reflexões e/ou implicações apresentadas?

\section{Caminhos metodológicos}

O corpus sobre o qual recaiu a análise é formado por 6061 artigos/comunicações analisados em quatro periódicos e quatro congressos científicos. Esta é uma pesquisa bibliográfica, que toma como base o primeiro decênio da Web 2.0, que compreende do ano de 2005 até 2015, apresentando os trabalhos que já foram discutidos sobre o tema Web 2.0 no Ensino de Química (propostas, discussões, aplicações de ferramentas, elaboração de materiais etc.). Essa revisão da literatura é uma parte dos resultados de uma pesquisa de mestrado, com dissertação defendida no programa de Pós-Graduação em Ensino de Ciências de uma Universidade Federal, cujo objetivo foi investigar as contribuições do uso de ferramentas da Web 2.0 no Ensino de Química.

A metodologia para o desenvolvimento da presente pesquisa percorreu três etapas:

(I) Busca e download de artigos publicados nos sítios das revistas científicas e de congressos específicos. Como critério de seleção dos periódicos, optamos por aqueles que apresentassem qualidade de produção intelectual na área de ensino de Ciências, em especial de Ensino de Química, e que também fossem acessíveis gratuitamente na internet. Com relação aos artigos/comunicações, selecionamos os que dissertassem sobre: Tecnologias da Informação e Comunicação (TIC), Web 2.0 e Ensino de Química. O conteúdo de cada artigo/comunicação foi analisado separadamente pelos pesquisadores, até saturação dos dados para identificar a orientação dominante da pesquisa, seu contexto, a síntese dos resultados e as conclusões ou implicações;

(II) Classificação das informações pretendidas (Período de Publicação, Publicação sobre TIC no ensino, Publicação sobre Web 2.0);

(III) Análise e quantificação das informações para elaboração de tabelas visando extrair considerações sobre as ferramentas da Web 2.0 no Ensino de Química. Nessa etapa descrevemos alguns trabalhos analisados, discutindo sobre o uso da Web 2.0 nos processos de ensino e aprendizagem de Química.

No que se refere à etapa I, analisamos dois periódicos de amplo alcance em língua portuguesa: Revista Brasileira de Informática na Educação (RBIE) e Revista Química Nova na Escola (QNEsc) que apresentam trabalhos pertinentes sobre educação (Química) e/ou tecnologias (no ensino); e dois periódicos que apresentam diversas publicações de pesquisadores no âmbito ibero-americano e europeu sobre tecnologias na educação e Ensino de Ciências (Química): Revista Enseñanza de las Ciencias e eLearning Papers. A escolha por esses periódicos deve-se ao fato que veiculam de forma mais explícita a produção ligada às tecnologias na educação e têm amplo alcance por docentes e discentes da área de Ensino de Química.

No que diz respeito aos congressos, nossa escolha priorizou aqueles trabalhos com foco nos processos de ensino e aprendizagem, que contribuem com aspectos relacionados às tecnologias no ensino e no Ensino de Ciências (Química), sendo escolhidos: o Encontro Nacional de Ensino de Química, a Rede Ibero-Americana de Informática na Educação, o Taller Internacional de Software Educativo e o Congresso Ibero-americano de Informática Educativa.

Em relação a nossa análise, seguimos as considerações de Lüdke e André (2012) organizando os dados coletados, colocando-os em partes, encontrando relações entre eles e buscando identificar tendências nessas relações. Nesse contexto, a análise contribuiu para a reinterpretação das mensagens presentes nos textos com a finalidade de alcançar uma compreensão de seus significados relacionados ao objetivo desta pesquisa. 
A seguir, destacamos este estudo em três seções: na primeira, apresentamos os resultados da análise dos periódicos; na segunda, as observações em relação aos congressos selecionados; e, na terceira, a análise de alguns trabalhos sobre Ensino de Química e Web 2.0 observados durante a pesquisa.

\section{O que dizem os periódicos?}

A importância que os periódicos possuem tem destaque no que diz respeito à qualidade da pesquisa e ao avanço do conhecimento (Meli \& Oliveira Neto, 2011). Assim, apresentamos uma breve análise dos periódicos.

Foram analisados 1280 artigos publicados no período de 2005 a 2015 através da leitura dos resumos/abstracts dos textos. Quando estes apresentavam algumas características de ferramentas da Web 2.0, uma análise completa da obra era realizada. Os quatro periódicos selecionados tiveram suas escolhas com base nos critérios de expressividade e acessibilidade, considerando-se a importância da instituição divulgadora e sua circulação, em âmbito Nacional e Internacional. Os dois primeiros periódicos são expressivos na área de ensino/educação (Ensino de Química e Ensino de Ciências) que têm divulgação aberta para as tecnologias no ensino. E os dois últimos destacam-se na área de pesquisa em TIC na educação (RBIE e eLearning Papers), em que está inserido o contexto da Web 2.0.

\subsection{QNEsc}

No que tange aos periódicos acadêmicos da área de Ensino de Química, a Revista Química Nova na Escola (QNEsc), criada em 1995 com uma periodicidade semestral e, a partir de 2008, trimestral, propõe-se a subsidiar o trabalho, a formação e a atualização da comunidade brasileira do Ensino de Química. A QNEsc integra-se à linha editorial da Sociedade Brasileira de Química e tem um espaço aberto ao educador, que suscita debates e reflexões sobre o ensino e a aprendizagem de química.

Das seções para publicação da QNEsc, a utilizada para análise deste trabalho foi: Educação em Química e Multimídia. Esta seção visa a aproximar o leitor das aplicações das tecnologias da informação e comunicação no contexto do ensino-aprendizado de Química, publicando resenhas de produtos e artigos/notas teóricos e técnicos. A Tabela 1 apresenta os resultados de nossa pesquisa:

Tabela 1: Artigos publicados na Revista QNEsc entre 2005-2015.

\begin{tabular}{|c|c|c|c|c|c|c|c|}
\hline $\begin{array}{l}\text { Ano/volume } \\
\text { /número }\end{array}$ & $\begin{array}{l}\text { Total de } \\
\text { artigos }\end{array}$ & $\begin{array}{c}\text { Sobre } \\
\text { Tecnologias } \\
\text { no Ensino } \\
\end{array}$ & $\begin{array}{c}\text { Com } \\
\text { ênfase na } \\
\text { Web } 2.0 \\
\end{array}$ & $\begin{array}{l}\text { Ano/volume } \\
\text { /número }\end{array}$ & $\begin{array}{c}\text { Total de } \\
\text { artigos }\end{array}$ & $\begin{array}{c}\text { Sobre } \\
\text { Tecnologias } \\
\text { no Ensino } \\
\end{array}$ & $\begin{array}{l}\text { Com ênfase } \\
\text { na Web } 2.0\end{array}$ \\
\hline $\begin{array}{l}2005 / 21 \\
2005 / 22\end{array}$ & $\begin{array}{l}10 \\
10\end{array}$ & $\begin{array}{l}0 \\
1\end{array}$ & $\begin{array}{c}\text { Nenhum } \\
\text { dos artigos } \\
\text { apresentou. }\end{array}$ & $\begin{array}{l}2011 / 33(1) \\
2011 / 33(2) \\
2011 / 33(3) \\
2011 / 33(4)\end{array}$ & $\begin{array}{l}9 \\
8 \\
7 \\
8\end{array}$ & $\begin{array}{l}0 \\
1 \\
0 \\
0\end{array}$ & $\begin{array}{l}\text { Nenhum dos } \\
\text { artigos } \\
\text { apresentou. }\end{array}$ \\
\hline $\begin{array}{l}2006 / 23 \\
2006 / 24\end{array}$ & $\begin{array}{l}12 \\
10\end{array}$ & $\begin{array}{l}0 \\
1\end{array}$ & $\begin{array}{l}\text { Nenhum } \\
\text { dos artigos } \\
\text { apresentou. }\end{array}$ & $\begin{array}{l}2012 / 34(1) \\
2012 / 34(2) \\
2012 / 34(3) \\
2012 / 34(4) \\
\end{array}$ & $\begin{array}{c}6 \\
6 \\
7 \\
12 \\
\end{array}$ & $\begin{array}{l}0 \\
0 \\
0 \\
1 \\
\end{array}$ & $\begin{array}{l}\text { Nenhum dos } \\
\text { artigos } \\
\text { apresentou. }\end{array}$ \\
\hline $\begin{array}{l}2007 / 25 \\
2007 / 26\end{array}$ & $\begin{array}{l}11 \\
11\end{array}$ & Nenhum & $\begin{array}{l}\text { Nenhum } \\
\text { dos artigos } \\
\text { apresentou. }\end{array}$ & $\begin{array}{l}2013 / 35(1) \\
2013 / 35(2) \\
2013 / 35(3) \\
2013 / 35(4)\end{array}$ & $\begin{array}{l}8 \\
9 \\
9 \\
9\end{array}$ & $\begin{array}{l}0 \\
0 \\
2 \\
0\end{array}$ & $\begin{array}{l}\text { Nenhum dos } \\
\text { artigos } \\
\text { apresentou. }\end{array}$ \\
\hline $\begin{array}{l}2008 / 27 \\
2008 / 28 \\
2008 / 29\end{array}$ & $\begin{array}{l}10 \\
10 \\
11\end{array}$ & $\begin{array}{l}0 \\
0 \\
0\end{array}$ & $\begin{array}{l}0 \\
0 \\
0\end{array}$ & $\begin{array}{l}2014 / 36(1) \\
2014 / 36(2) \\
2014 / 36(3)\end{array}$ & $\begin{array}{l}8 \\
9 \\
9\end{array}$ & $\begin{array}{l}1 \\
0 \\
1\end{array}$ & $\begin{array}{l}1 \\
0 \\
0\end{array}$ \\
\hline
\end{tabular}




\begin{tabular}{c|c|c|c|c|c|c|c}
\hline $2008 / 30$ & 13 & 1 & 1 & $2014 / 36(4)$ & 9 & 0 & 0 \\
\hline $2009 / 31(1)$ & 10 & 0 & 0 & $2015 / 37(1)$ & 10 & 0 & Nenhum dos \\
$2009 / 31(2)$ & 11 & 1 & 1 & $2015 / 37(2)$ & 10 & 0 & artigos \\
$2009 / 31(3)$ & 10 & 0 & 0 & $2015 / 37(3)$ & 10 & 0 & apresentou. \\
$2009 / 31(4)$ & 10 & 1 & 0 & $2015 / 37(4)$ & 10 & & \\
\hline $2010 / 32(1)$ & 9 & 0 & Nenhum & & & & \\
$2010 / 32(2)$ & 9 & 0 & dos artigos & & & & \\
$2010 / 32(3)$ & 9 & 0 & apresentou. & & & & \\
$2010 / 32(4)$ & 7 & 1 & a & 1 & & & \\
\hline
\end{tabular}

As ferramentas da Web 2.0 são pouco exploradas no conjunto das publicações dessa revista, configurando menos de 1\% do total dos 356 artigos analisados. Percebemos que nas publicações de QNEsc a presença de artigos envolvendo as TIC é ínfima, 3,9\% do total, embora destaque-se a existência de muitos trabalhos nessa área (como observado em congressos da área), esse número de publicações é preocupante se atentarmos para a grande presença das tecnologias nas escolas e na sociedade.

\subsection{Enseñanza de las Ciencias}

A revista Enseñanza de las Ciencias é um periódico com publicações de três números por ano. Desde a publicação de seu primeiro número, em março de 1983, a revista tem se consolidado como um ponto de referência, especialmente entre os profissionais do campo do ensino de matemática e ciências experimentais da Espanha e Ibero-América. São alguns dos objetivos: em relação com o campo do ensino de ciências, aprofundar a base teórica dos estudos e investigações publicadas, promover estudos que correspondam às necessidades dos professores das áreas de ciências e matemática. Os dados expostos na Tabela 2 refletem as publicações da revista no período proposto (2005-2015).

Tabela 2: Artigos publicados entre 2005-2015 na Revista Enseñanza de las Ciencias.

\begin{tabular}{|c|c|c|c|c|c|c|c|}
\hline $\begin{array}{l}\text { Ano/volume } \\
\text { /número }\end{array}$ & $\begin{array}{l}\text { Total de } \\
\text { artigos }\end{array}$ & $\begin{array}{c}\text { Sobre } \\
\text { Tecnologias } \\
\text { no Ensino } \\
\end{array}$ & $\begin{array}{c}\text { Com } \\
\text { ênfase na } \\
\text { Web } 2.0 \\
\end{array}$ & $\begin{array}{l}\text { Ano/volume } \\
\text { /número }\end{array}$ & $\begin{array}{l}\text { Total de } \\
\text { artigos }\end{array}$ & $\begin{array}{c}\text { Sobre } \\
\text { Tecnologias } \\
\text { no Ensino } \\
\end{array}$ & $\begin{array}{l}\text { Com ênfase } \\
\text { na Web } 2.0\end{array}$ \\
\hline $\begin{array}{l}2005 / 21 \\
2005 / 22\end{array}$ & $\begin{array}{l}10 \\
10\end{array}$ & $\begin{array}{l}0 \\
1\end{array}$ & $\begin{array}{c}\text { Nenhum } \\
\text { dos artigos } \\
\text { apresentou. }\end{array}$ & $\begin{array}{l}2011 / 33(1) \\
2011 / 33(2) \\
2011 / 33(3) \\
2011 / 33(4) \\
\end{array}$ & $\begin{array}{l}9 \\
8 \\
7 \\
8 \\
\end{array}$ & $\begin{array}{l}0 \\
1 \\
0 \\
0 \\
\end{array}$ & $\begin{array}{l}\text { Nenhum dos } \\
\text { artigos } \\
\text { apresentou. }\end{array}$ \\
\hline $\begin{array}{l}2006 / 23 \\
2006 / 24\end{array}$ & $\begin{array}{l}12 \\
10\end{array}$ & $\begin{array}{l}0 \\
1\end{array}$ & $\begin{array}{c}\text { Nenhum } \\
\text { dos artigos } \\
\text { apresentou. }\end{array}$ & $\begin{array}{l}2012 / 34(1) \\
2012 / 34(2) \\
2012 / 34(3) \\
2012 / 34(4) \\
\end{array}$ & $\begin{array}{c}6 \\
6 \\
7 \\
12 \\
\end{array}$ & $\begin{array}{l}0 \\
0 \\
0 \\
1 \\
\end{array}$ & $\begin{array}{l}\text { Nenhum dos } \\
\text { artigos } \\
\text { apresentou. }\end{array}$ \\
\hline $\begin{array}{l}2007 / 25 \\
2007 / 26\end{array}$ & $\begin{array}{l}11 \\
11\end{array}$ & Nenhum & $\begin{array}{l}\text { Nenhum } \\
\text { dos artigos } \\
\text { apresentou. }\end{array}$ & $\begin{array}{l}2013 / 35(1) \\
2013 / 35(2) \\
2013 / 35(3) \\
2013 / 35(4)\end{array}$ & $\begin{array}{l}8 \\
9 \\
9 \\
9\end{array}$ & $\begin{array}{l}0 \\
0 \\
2 \\
0\end{array}$ & $\begin{array}{l}\text { Nenhum dos } \\
\text { artigos } \\
\text { apresentou. }\end{array}$ \\
\hline $\begin{array}{l}2008 / 27 \\
2008 / 28 \\
2008 / 29 \\
2008 / 30 \\
\end{array}$ & $\begin{array}{l}10 \\
10 \\
11 \\
13\end{array}$ & $\begin{array}{l}0 \\
0 \\
0 \\
1\end{array}$ & $\begin{array}{l}0 \\
0 \\
0 \\
1\end{array}$ & $\begin{array}{l}2014 / 36(1) \\
2014 / 36(2) \\
2014 / 36(3) \\
2014 / 36(4)\end{array}$ & $\begin{array}{l}8 \\
9 \\
9 \\
9\end{array}$ & $\begin{array}{l}1 \\
0 \\
1 \\
0\end{array}$ & $\begin{array}{l}1 \\
0 \\
0 \\
0\end{array}$ \\
\hline $\begin{array}{l}2009 / 31(1) \\
2009 / 31(2) \\
2009 / 31(3) \\
2009 / 31(4) \\
\end{array}$ & $\begin{array}{l}10 \\
11 \\
10 \\
10 \\
\end{array}$ & $\begin{array}{l}0 \\
1 \\
0 \\
1 \\
\end{array}$ & $\begin{array}{l}0 \\
1 \\
0 \\
0\end{array}$ & $\begin{array}{l}2015 / 37(1) \\
2015 / 37(2) \\
2015 / 37(3) \\
2015 / 37(4) \\
\end{array}$ & $\begin{array}{l}10 \\
10 \\
10 \\
10 \\
\end{array}$ & $\begin{array}{l}0 \\
0 \\
0 \\
1 \\
\end{array}$ & $\begin{array}{l}\text { Nenhum dos } \\
\text { artigos } \\
\text { apresentou. }\end{array}$ \\
\hline $\begin{array}{l}2010 / 32(1) \\
2010 / 32(2) \\
2010 / 32(3) \\
2010 / 32(4)\end{array}$ & $\begin{array}{l}9 \\
9 \\
9 \\
7\end{array}$ & $\begin{array}{l}0 \\
0 \\
0 \\
1\end{array}$ & $\begin{array}{c}\text { Nenhum } \\
\text { dos artigos } \\
\text { apresentou. }\end{array}$ & & & & \\
\hline
\end{tabular}


Foram analisados 397 artigos publicados durante os anos de 2005 a 2015 e, destes, pouco mais de $2 \%$ eram voltados para as tecnologias no ensino, o que reflete na publicação de apenas dois trabalhos com ênfase na Web 2.0. Embora a Revista seja voltada para o Ensino de Ciências, a área de Tecnologias da Informação e Comunicação ainda é incipiente na realidade deste periódico, o que deixa em aberto muitas indagações sobre os aspectos da aplicação de ferramentas da Web 2.0 e de processos e práticas por pesquisadores no âmbito Ibero-americano.

\subsection{RBIE}

A Revista Brasileira de Informática na Educação (RBIE) é publicada em três edições anuais. A revista busca reunir os trabalhos dos profissionais e pesquisadores na área de Informática na Educação, procurando disseminar métodos e técnicas para o uso efetivo da informática no processo educativo, de acordo com a realidade brasileira. É mantida pela Comissão Especial de Informática na Educação da Sociedade Brasileira de Computação. Os principais objetivos da revista são: divulgar a produção científica dos grupos de pesquisa vinculados às instituições de ensino que trabalham com Informática na Educação; propiciar um espaço de reflexão acerca das questões do cotidiano da prática de ensino mediada pelo computador; estimular a produção científica em nível de graduação e pós-graduação; entre outros.

Ao todo foram estudados 247 artigos publicados desde o surgimento da Web 2.0, verificando-se, posteriormente, 37 artigos publicados envolvendo a Web 2.0 (cerca de 15\%). Destes, apenas dois artigos envolvem o Blog e 20 são sobre ambiente virtual de aprendizagem. É importante destacar que na busca da palavra-chave "TIC", utilizando o mecanismo de busca disponível no site da revista, apenas 7 publicações foram contempladas, o que não representa 0 número total de artigos publicados no período pesquisado.

\section{4 eLearning Papers}

A eLearning Papers propõe uma nova dimensão ao intercâmbio de informações sobre o $e$ learning na Europa e o incentivo à investigação. Assim, seus artigos apresentam pontos de vista sobre a situação atual e as tendências do e-learning em comunidades distintas: nas escolas, nas universidades, nas empresas, na sociedade civil e nas instituições. Por intermédio dos seus artigos, esta revista visa promover a utilização das TIC nos processos de ensino e aprendizagem. A revista eLearning Papers é publicada cinco vezes por ano. Para cada artigo há um sumário disponível em 21 línguas. O texto integral é disponível na língua de origem e conta com mais de 30.000 utilizadores registrados na comunidade www.elearningeuropa.info.

O âmbito da eLearning Papers reflete as quatro áreas de interesse do elearningeuropa.info: escolas, educação superior, educação e emprego e educação e sociedade. São aceitos todos os temas relacionados com o e-learning. Alguns temas exemplificativos: Tecnologias; Pedagogia; Processo; Qualidade e avaliação; eInclusão; Ambientes de aprendizagem. Na análise das publicações destrinchamos as atividades por ano. A revista iniciou as divulgações científicas em 2006, portanto após a conferência de O’Reilly sobre a Web 2.0 (O’Reilly, 2005). A Tabela 3 apresenta uma síntese dos trabalhos envolvendo a Web 2.0.

Tabela 3: Artigos publicados entre 2006-2015 na Revista eLearning Papers.

\begin{tabular}{c|c|c|c|c|c|c|c|c|c|c}
\hline Ano & $\mathbf{2 0 0 6}$ & $\mathbf{2 0 0 7}$ & $\mathbf{2 0 0 8}$ & $\mathbf{2 0 0 9}$ & $\mathbf{2 0 1 0}$ & $\mathbf{2 0 1 1}$ & $\mathbf{2 0 1 2}$ & $\mathbf{2 0 1 3}$ & $\mathbf{2 0 1 4}$ & $\mathbf{2 0 1 5}$ \\
\hline Total de publicações & 5 & 25 & 25 & 25 & 25 & 36 & 32 & 28 & 30 & 49 \\
\hline Sobre a Web 2.0 & 1 & 9 & 9 & 8 & 1 & 14 & 10 & 10 & 0 & 18 \\
\hline
\end{tabular}

A partir dos dados descritos na Tabela 3, dos 280 artigos divulgados pela revista, 80 (28,5\%) estavam relacionados com as ferramentas da Web 2.0. 
Nesta primeira etapa da pesquisa, destacamos os periódicos analisados que apresentam publicações sobre a Web 2.0. Cabe ressaltar que, dos quatro periódicos analisados, a eLearning Papers concentrou maior número percentual de artigos sobre Web 2.0, aproximadamente 29\%, seguido da Revista Brasileira de Informática na Educação com cerca de 15\%. Ao todo foram analisadas 1280 publicações nos quatro periódicos, sendo que 122 artigos (9,5\%) são referentes a ferramentas da Web 2.0. É importante destacar que 18 artigos (1,4\%) analisados são referentes ao uso de ferramentas da Web 2.0 no Ensino de Química.

\section{O que revelam os trabalhos em congressos?}

A seguir destacamos quatro eventos de grande relevância, sendo considerados importantes ao tratarem dos aspectos educacionais e/ou tecnológicos, dentro da comunidade de educadores químicos. Ao total foram analisadas 4781 comunicações.

\subsection{ENEQ}

O Encontro Nacional de Ensino de Química (ENEQ) é um evento bienal organizado pela Divisão de Ensino de Química da Sociedade Brasileira de Química (SBQ) desde 1982, e que até 1992 foi realizado em conjunto com a Reunião Anual da Sociedade Brasileira para o Progresso da Ciência. Este encontro ocorre em diferentes universidades espalhadas pelo Brasil. O ENEQ é o principal e mais tradicional evento na área de pesquisa em Ensino de Química realizado no Brasil e articulase em torno dos seguintes objetivos: (1) congregar professores, pesquisadores, estudantes e demais interessados na área de Educação Química, envolvidos na educação básica e no nível superior, com o ensino e com a formação em Química, promovendo interações, ações e construções para participar de debates em torno dos avanços e dilemas vivenciados na Área; (2) socializar e discutir ideias e produções, na perspectiva da explicitação e da reflexão crítica sobre atuais tendências, concepções e práticas na área, com vistas a contribuir na construção de uma nova inserção da formação em Química na sociedade e na tecnologia contemporâneas; (3) intensificar a interlocução de grupos de pesquisa e desenvolvimento atuantes em linhas temáticas da Área da Educação Química, inter-relacionando e alimentando conhecimentos, ações e mudanças junto a comunidades, em âmbitos local, regional e nacional, incrementando e articulando contatos diversificados concernentes a produções científicas socialmente relevantes.

O ENEQ realizado em 2006 foi promovido pela Universidade de Campinas (Unicamp). O encontro contou com a participação de 1058 inscritos, sendo 56\% estudantes de graduação, 34\% estudantes de pós-graduação e professores da educação básica e 10\% professores universitários. Quanto ao número de trabalhos foram: 334 trabalhos apresentados, sendo 250 na forma de resumos de painéis e 84 na forma de trabalho completo, dos quais 24 foram apresentados em sessões coordenadas. Na área das TIC foram apresentados 18 trabalhos e, destes, 05 continham elementos mínimos (blogs, ambientes virtuais de aprendizagem e wikis) necessários para que os identificassem como recursos da Web 2.0.

No ano de 2008 o ENEQ foi realizado na Universidade Federal do Paraná (UFPR), com a participação de 1.270 inscritos, sendo 56\% estudantes de graduação, 14\% estudantes de pósgraduação, 20\% de professores da educação básica e 10\% professores universitários. Este evento contou com 462 trabalhos aceitos para apresentação no evento, sendo 262 na forma de resumos de painéis e 200 na forma de trabalho completo, dos quais 93 foram apresentados em sessões coordenadas. Na área temática das TIC foram expostos 38 trabalhos, 8,3\% do total de trabalhos apresentados. Destes trabalhos, encontramos 09 que incorporaram as características da Web 2.0, isto é, dos 38 trabalhos que envolvem as TIC neste congresso, 23,6\% expuseram características de ferramentas da Web 2.0. 
Organizado na Universidade de Brasília (UnB), o ENEQ de 2010 contabilizou mais de 1.700 inscrições, feitas por professores, pesquisadores e estudantes de diversas instituições de ensino. Foram submetidos cerca de 300 trabalhos completos e mais de 500 resumos, refletindo o perfil e os avanços da comunidade de pesquisadores em Ensino de Química do país. Para a área das TIC foram apresentados 33 trabalhos e os que discutiram sobre a Web 2.0 (características, aplicações, análises) foram ao todo 11 trabalhos.

A Universidade Federal da Bahia (UFBA) ficou responsável para promover o ENEQ de 2012. Neste ano o evento comemorava 30 anos de congregação dos educadores químicos, contando com a presença de 1.952 participantes com 889 trabalhos publicados, sendo 5,8\% direcionados as TIC e Ensino de Química. Em nossa análise encontramos 14 (1,6\%) publicações envolvendo ferramentas da Web 2.0.

Em 2014 o ENEQ aconteceu na Universidade Federal de Ouro Preto (UFOP). Para este evento foram apresentados 1069 trabalhos, dos quais 4,7\% envolviam as tecnologias da informação e comunicação, sendo sete trabalhos (ou seja menos de 1\%) sobre ferramentas da Web 2.0 .

Em nossa análise observamos o aumento no número de publicações envolvendo as TIC no Ensino de Química, em 2006 foram 18 trabalhos, já em 2014 publicaram-se 51, ou seja, um aumento de quase $200 \%$ (Gráfico 1). Além disso, os dados obtidos durante a pesquisa indicam que os ambientes virtuais de aprendizagem e as Webquests são os recursos que mais se destacam entre as TIC que fazem uso de ferramentas da Web 2.0, principalmente nos eventos entre 2010 e 2012. Entretanto, pesquisas voltadas para blogs, redes sociais e outros recursos da Web 2.0 têm demonstrado um crescimento exponencial, seguindo a tendência da evolução da World Wide Web, em que a interação do criador com o usuário é cada vez mais intensa (Mello, 2010). Ademais, o desenvolvimento de novos métodos educacionais para o ensino se torna mais acessível e a Web 2.0 destaca seu potencial, oferecendo aos usuários motivação para os processos de ensino e aprendizagem.

Gráfico 1: Evolução temporal das comunicações em TIC e Web 2.0 no Ensino de Química. A linha cinza indica o crescimento linear dessas comunicações em TIC.

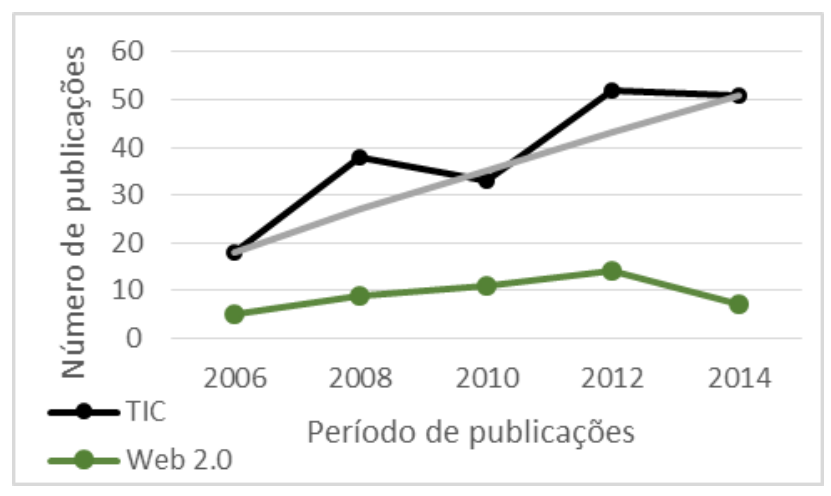

Apesar de as publicações na área não serem homogêneas no período, observa-se pela linha de tendência do gráfico 1 uma sinalização de crescimento.

\subsection{RIBIE}

A Rede Ibero-Americana de Informática na Educação (RIBIE) nasceu como uma ideia e área estratégica do programa CYTED - Ciência e Tecnologia para o Desenvolvimento, integrado por órgãos governamentais de cada um dos países da América Latina e da Península Ibérica. O propósito geral da RIBIE, desde sua fundação, tem sido melhorar a Educação no contexto IberoAmericano com o uso das Tecnologias da Informação e Comunicação. Sendo assim busca reunir 
os esforços dos 21 países integrantes, a fim de desenvolver ações que potencializem a identificação e os intercâmbios entre os grupos de investigação e desenvolvimento que atuam na área da Informática aplicada à Educação.

A RIBIE tem suas edições ocorrendo anualmente e, a cada dois anos, dentro da sua realização é organizado o Congresso Ibero-americano de Informática Educativa, que se tornou o evento de referência sobre Informática Educativa no espaço ibero-americano. A única exceção foi a realização do congresso que ocorreria em 2014 no ano de 2015. Para os eventos realizados pela RBIE elucidamos de forma sucinta os trabalhos relativos com as ferramentas da Web 2.0 na tabela 4.

Tabela 4: Número de comunicações publicadas na RIBIE entre 2005-2015.

\begin{tabular}{c|c|c|c|c|c|c|c|c|c|c|c}
\hline Ano & $\mathbf{2 0 0 5}$ & $\mathbf{2 0 0 6}$ & $\mathbf{2 0 0 7}$ & $\mathbf{2 0 0 8}$ & $\mathbf{2 0 0 9}$ & $\mathbf{2 0 1 0}$ & $\mathbf{2 0 1 1}$ & $\mathbf{2 0 1 2}$ & $\mathbf{2 0 1 3}$ & $\mathbf{2 0 1 4}$ & $\mathbf{2 0 1 5}$ \\
\hline Total de publicações & 5 & 15 & 25 & 25 & 25 & 25 & 36 & 32 & 28 & 30 & 49 \\
\hline Sobre a Web 2.0 & 1 & 2 & 9 & 9 & 8 & 1 & 14 & 10 & 10 & 0 & 18 \\
\hline
\end{tabular}

Todos os trabalhos passam por um processo de revisão anônima, com colaboradores tanto ibero-americanos como europeus. Os países em que ocorreram o congresso da RIBIE foram: Costa Rica (2006), Venezuela (2008), Chile (2010) e Colômbia (2012 e 2015).

Dada a característica do RIBIE com trabalhos na área da informática na educação, observamos que, do total de trabalhos apresentados (419), 52 tratavam sobre a Web 2.0 e apenas oito (8) eram relacionados com o Ensino de Química.

\subsection{TISE}

O Taller Internacional de Software Educativo (TISE) é um evento que ocorre anualmente no mês de dezembro em Santiago, no Chile. Um dos objetivos deste evento é reunir em um espaço apresentações, intercâmbios e difusão de experiências nacionais e internacionais sobre Informática Educativa em diversas áreas: desenho, desenvolvimento e avaliação de software educativo; experiências inovadoras das TIC na educação; metodologias de uso de TIC de apoio à aprendizagem; aspectos sociais das TIC em contextos educativos; formação de professores em TIC; entre outras.

No período, entre 2005 e 2015, foram publicados 691 trabalhos no TISE, oriundos de diversos investigadores do Brasil, Chile, Cuba, Colômbia, Espanha, Paraguai, Guatemala, Peru, México, Venezuela, Costa Rica, Trinidade e Tobago entre outros. A Tabela 5 apresenta o número total de trabalhos publicados em relação às ferramentas da Web 2.0.

Tabela 5: Número de comunicações publicadas no TISE entre 2005-2015.

\begin{tabular}{c|c|c|c|c|c|c|c|c|c|c|c}
\hline Ano & $\mathbf{2 0 0 5}$ & $\mathbf{2 0 0 6}$ & $\mathbf{2 0 0 7}$ & $\mathbf{2 0 0 8}$ & $\mathbf{2 0 0 9}$ & $\mathbf{2 0 1 0}$ & $\mathbf{2 0 1 1}$ & $\mathbf{2 0 1 2}$ & $\mathbf{2 0 1 3}$ & $\mathbf{2 0 1 4}$ & $\mathbf{2 0 1 5}$ \\
\hline Total de publicações & 34 & 22 & 24 & 27 & 24 & - & 48 & 87 & 159 & 145 & 121 \\
\hline Sobre a Web 2.0 & 8 & 8 & 8 & 3 & 4 & - & 4 & 6 & 14 & 13 & 17 \\
\hline
\end{tabular}

Embora o número de artigos publicados no evento tenha aumentado significativamente entre 2009 e 2013, o mesmo não acontece com os trabalhos envolvendo ferramentas da Web 2.0 (Gráfico 2).

Gráfico 2: Total de publicações no TISE por ano em relação as publicações sobre a Web 2.0 no mesmo ano. O eixo Y representa o número total de publicações relativas ao ano (eixo X). 


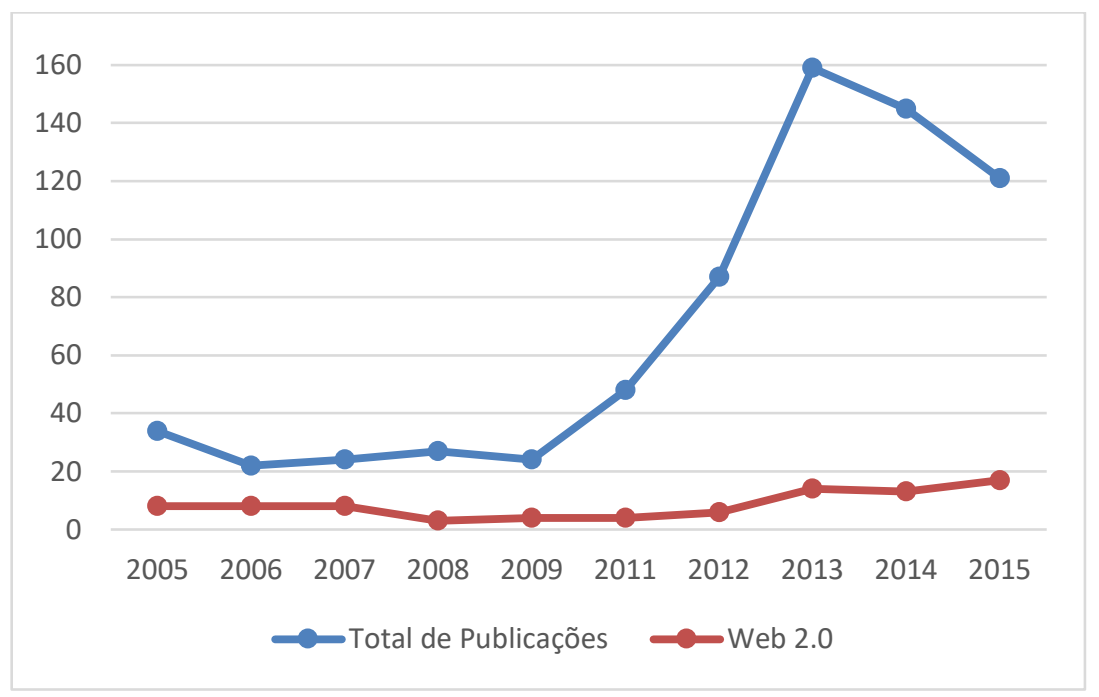

Destes trabalhos observamos que nove eram sobre Ensino de Química. É importante destacar que as temáticas mais recorrentes no TISE foram: experiências de aprendizagem com o apoio da Internet, aprendizagem baseada em jogos, impacto e efetividade das TIC na aprendizagem, interfaces para pessoas com limitações, metodologias de desenho, desenvolvimento e avaliação de software, modelos de interfaces interativas, modelos técnicos e pedagógicos, plataformas e ferramentas para a educação, recursos e ferramentas educativas Web 2.0 e aprendizagem facilitada pela tecnologia.

No ano de 2010, o XV TISE, assim como o RIBIE 2010, uniram-se ao Congresso Iberoamericano de Informática Educativa (IE) 2010, realizando um grande evento sobre tecnologias na educação. Trataremos deste congresso na próxima seção.

\subsection{IE}

O Congresso Ibero-americano de Informática Educativa (IE) 2010 é a união dos três eventos ibero-americanos mais importantes de Informática Educativa: O Congresso da Rede IberoAmericana de Informática Educativa (RIBIE), o Simpósio Internacional de Informática Educativa (SIEE) e o Taller Internacional de Software Educativo (TISE). O espírito do IE 2010 foi reunir os grandes expoentes da Ibero-América e do mundo para formar um espaço de apresentação, intercâmbio e difusão de experiências sobre informática educativa, em especial nas seguintes áreas: novas tendências na aprendizagem com tecnologia digital; e-Learning e e-Inclusão; interação pessoa-computador; desenho, desenvolvimento, avaliação, usos e aplicações de software educativo e Internet.

Este congresso ocorreu de forma especial pela segunda vez em 2010 (www.ie2010.cl). Foram aceitos 45 artigos completos (full papers), 65 pôsteres com artigos estendidos e 7 pôsteres com papers curtos, totalizando 117 publicações. Com isto, o total de aceitação de artigos completos foi de 38,4\%, 55,6\% para pôsteres com artigos estendidos e 6\% para pôsteres com papers curtos. As versões dos trabalhos selecionados foram provenientes da Espanha, Chile, Brasil, Argentina, Portugal, Colômbia, Estados Unidos, Uruguai, Venezuela, México, Costa Rica, Peru, França e Panamá. Temos um total de 34 trabalhos (29\%), que se identificaram com recursos da Web 2.0, dos quais 6 (5\%) eram no Ensino de Química.

\section{Um breve resumo dos periódicos e congressos analisados}


Conforme evidenciado nas seções 3 e 4, os dados revelam que a partir de seu surgimento, em 2005, o número de publicações voltadas ao uso e aplicação de recursos da Web 2.0 têm crescido. Assim, os quatro eventos analisados na seção 4 totalizaram 4781 comunicações, e deste total 1419 (29,7\%) encontram-se na área das TIC e 217 (4,5\%) relacionados com ferramentas da Web 2.0. Em contraste, identificamos o percentual de 9,5\% de artigos sobre as ferramentas da Web 2.0 publicados nos quatro periódicos analisados (na seção 3). Ademais, a Tabela 6 descreve os dados analisados de todas as publicações descritos em três categorias: Trabalhos sobre TIC; Trabalhos sobre Web 2.0; Trabalhos sobre Web 2.0 no Ensino de Química (WEQ).

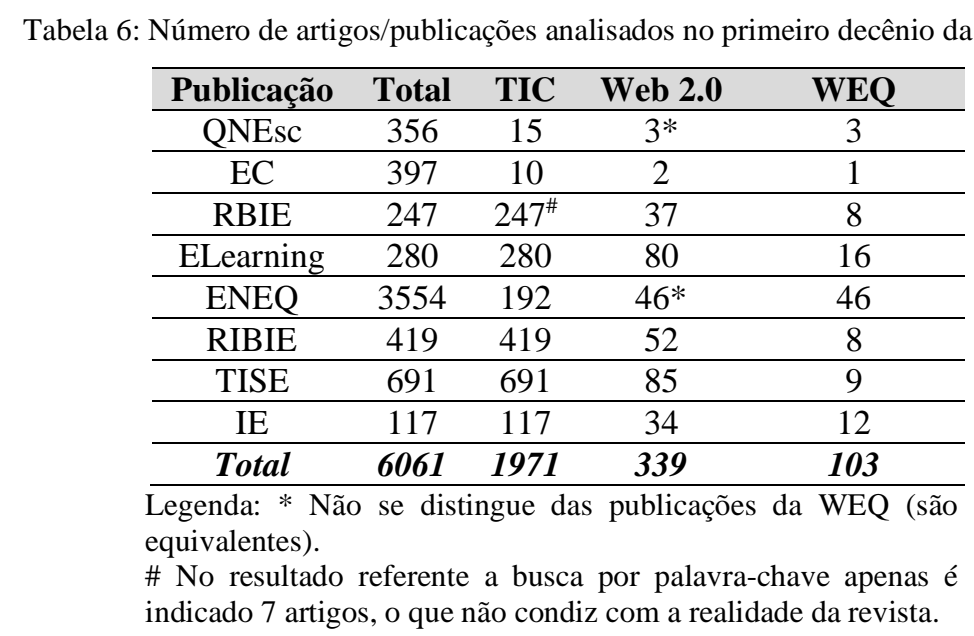

Os resultados apontam que, das 339 publicações sobre ferramentas da Web 2.0, 103 (30,3\%) tratam do seu uso direcionado exclusivamente ao Ensino de Química. Em termos percentuais, acreditamos que seja um número bastante relevante, considerando as inúmeras pesquisas que tratam sobre tecnologias e educação, isto é, praticamente 1/3 dos trabalhos são referentes à área de tecnologias no Ensino de Química.

Em média, foram publicados 179,2 artigos por ano sobre TIC (na qual a Web 2.0 está inserida), com um desvio padrão de 99,98, demonstrando a ausência de harmonização no número de publicações por ano na área analisada. Já quando analisamos apenas as publicações sobre ferramentas da Web 2.0, a média anual de publicação é de 30,81 artigos, com desvio padrão de 15,01. Os períodos de maior publicação sobre TIC/Web 2.0 foram 2012, com 386 artigos, representando 19,6\% do montante publicado em TIC, seguido de 2015 com 270 artigos, equivalente a $13,7 \%$.

Do período de 2005 a 2015 (primeiro decênio), foram investigados 6.061 artigos/comunicações, o que correspondeu a um total de 1971 publicações delimitadas pelas tecnologias da informação e comunicação e 339 referentes à Web 2.0. O gráfico 3 representa esta análise em percentual. 


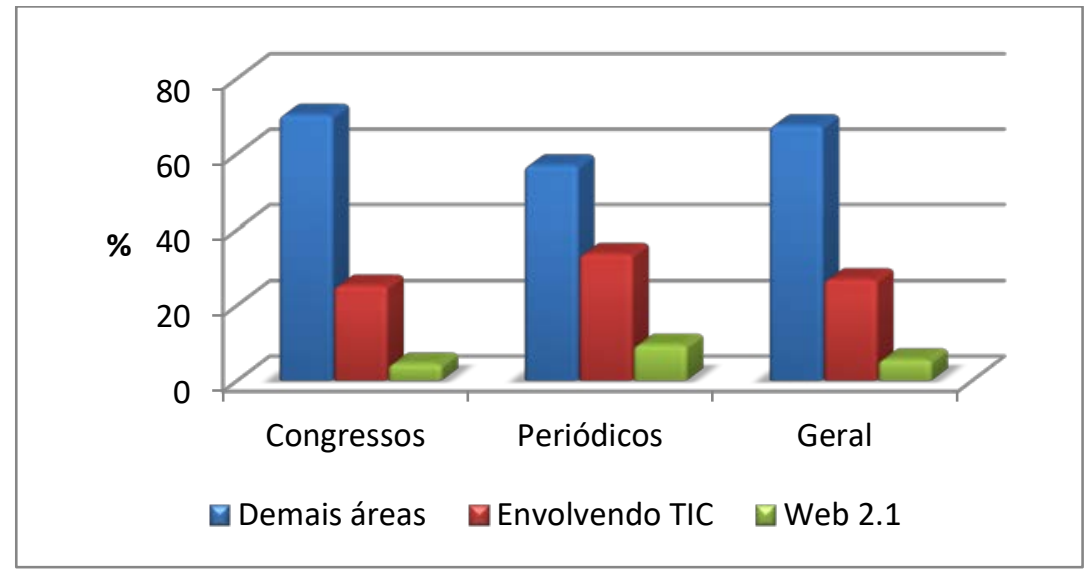

Quando comparamos as publicações dos periódicos e eventos analisados (1280 e 4781, respectivamente), em ambos os casos, observamos que os periódicos apresentam maior número de publicações envolvendo TIC (43,1\%) e sobre a Web 2.0 (9,5\%) que os eventos científicos analisados (29,7\% e 4,5\%, respectivamente). Numa perspectiva geral, os trabalhos envolvendo ferramentas da Web 2.0 apresentam um percentual em torno de $17 \%$ em relação a trabalhos envolvendo as TIC. É importante destacar que estes periódicos e eventos estão abertos para discussão sobre as tecnologias, entretanto boa parte dos trabalhos desses pesquisadores (professores e alunos) não tem como seu objeto de pesquisa o uso das tecnologias no Ensino de Química.

\section{O que foi produzido?}

Pelo levantamento realizado no período de 2005 a 2015 foram publicados 1971 artigos na área das TIC no ensino. Dessas publicações, 339 artigos são contribuições envolvendo a ferramenta da Web 2.0, publicados por 735 autores. Os resultados mostram que 90,2\% dos artigos foram publicados colaborativamente com outros autores, sendo que $47,8 \%$ dos artigos foram elaborados por dois autores, $39,8 \%$ por três autores, $0,9 \%$ por quatro e $1,7 \%$ por cinco ou mais autores, representando uma média de 2,3 autores por artigo.

Os resultados revelam uma significativa presença de parceria na autoria dos trabalhos (em 90,2\%) na área de tecnologias na educação. Acreditamos que trabalhos em coautoria possibilitam o fortalecimento de pesquisas tanto institucionais como interinstitucionais. Em nossos dados, observamos que trabalhos em coautoria estão mais presentes nas publicações de eventos (66\%) que em periódicos (34\%). Além disso, os dados corroboram com os descritos por Posada et al. (2016), em relação à frequência de publicação dos autores em um mesmo periódico/congresso. Neste caso, a RBIE tem uma distribuição mais uniforme de alguns autores em relação aos outros periódicos.

Em continuidade na nossa pesquisa, buscamos compreender as temáticas publicadas nos periódicos e eventos analisados. Os 339 artigos sobre Web 2.0 foram classificados pelas principais abordagens identificadas nos trabalhos, em cada um dos anos pesquisados (Tabela 7). Essa classificação considerou os temas e objetivos dos estudos.

Tabela 7: Assuntos abordados nas publicações envolvendo ferramentas da Web 2.0.

\begin{tabular}{cccccc}
\hline Ano & Blog & AV & RS & Outros & Total de artigos \\
\hline 2005 & 0 & 2 & 0 & 6 & 8 \\
\hline 2006 & 1 & 12 & 0 & 8 & 21 \\
\hline 2007 & 2 & 8 & 0 & 7 & 17 \\
\hline
\end{tabular}




\begin{tabular}{cccccc}
\hline 2008 & 9 & 12 & 5 & 19 & 45 \\
\hline 2009 & 1 & 4 & 2 & 6 & 13 \\
\hline 2010 & 8 & 17 & 4 & 19 & 48 \\
\hline 2011 & 0 & 1 & 3 & 49 & 53 \\
\hline 2012 & 10 & 9 & 5 & 25 & 49 \\
\hline 2013 & 2 & 4 & 2 & 17 & 25 \\
\hline 2014 & 3 & 6 & 5 & 7 & 21 \\
\hline 2015 & 1 & 10 & 4 & 24 & 39 \\
\hline Total & $\mathbf{3 7}$ & $\mathbf{8 5}$ & $\mathbf{3 0}$ & $\mathbf{1 8 7}$ & $\mathbf{3 3 9}$ \\
\hline \multicolumn{5}{c}{ Legenda: RS = Redes Sociais; AV = Ambientes virtuais. }
\end{tabular}

A Tabela 7 ilustra que a distribuição dos assuntos abordados não foi homogênea durante o período analisado. Contudo, apresenta a preferência por publicações envolvendo ambientes virtuais, seguida dos blogs. O ano de 2011 apresentou o maior número de artigos/comunicações publicados sobre as ferramentas da Web 2.0. Na categoria outros, que contempla softwares, uso de computador, celular, vídeos etc., os trabalhos envolvendo a elaboração e utilização de Webquests foram um dos mais presentes (23 artigos/publicações). Os dados na Tabela 7 apresentam os temas dos artigos/comunicações produzidos, destacando características do que se têm discutido em diferentes períodos e lugares, evidenciando, segundo Ferreira (2002), o papel do estado da arte.

A partir do refinamento realizado nos 339 artigos sobre ferramentas da Web 2.0, analisamos os 103 artigos/comunicações que tratam das ferramentas da Web 2.0 no Ensino de Química (WEQ). Obedecendo a categorização empregada na pesquisa (Tabela 7), apresentam-se, na sequência, os principais assuntos abordados das três categorias analisadas: blogs, redes sociais e ambientes virtuais. Escolhemos duas publicações (uma de um periódico e outra de um congresso) de cada categoria para, de forma concisa, descrevermos suas contribuições. A escolha baseou-se no número de citações que o artigo apresenta na plataforma do Google Scholar.

Sobre blog, o artigo (consultado na revista QNEsc) "Blogs na Formação Inicial de Professores de Química” (Barro, Baffa, \& Queiroz, 2013) relata o desenvolvimento e uso de blogs em uma disciplina de Prática do Ensino de Química. A construção do blog foi pautada na modalidade de aprendizado (Brownstein \& Klein, 2006), por envolver pesquisa, escrita, comentários e reflexões, possibilitando a interação por meio dos comentários. Foram realizadas análises qualitativa e quantitativa dos dados coletados no estudo, e os resultados da pesquisa indicam que há uma boa aceitação dos estudantes para utilizarem o blog como uma ferramenta de apoio ao ensino presencial, e que pode contribuir na interação entre professor e aluno. Este artigo reflete uma apropriação do blog e sua contribuição na formação de licenciandos em Química como recurso e estratégia pedagógica. No TISE 2015, o uso do blog é destacado por meio de uma análise da aplicabilidade e a aceitação de blogs na sala de aula (Caldeira, Silva, \& Magdalena, 2015). Assim como observamos na publicação de Barro, Baffa e Queiroz (2013) na QNEsc, no trabalho de Caldeira, Silva e Magdalena (2015), a análise dos blogs aponta (também) uma postura favorável dos alunos como um apoio ao processo de aprendizagem. Porém, neste caso são descritos quatro estudos de caso com diferentes maneiras de utilizar o blog como ferramenta educacional. O uso do blog, em ambos os casos, ocasionou mais dinamismo para a realização das atividades, além de facilitar a interação entre os envolvidos com a possibilidade de discutir ideias e opiniões sem que estejam no mesmo espaço físico.

Ao tratarmos dos ambientes virtuais, encontramos inúmeros estudos publicados. Por exemplo, na RBIE, o mapeamento das produções científicas sobre ambientes virtuais e objetos de aprendizagem são descritos por uma análise crítica do processo evolutivo em pesquisas nessa área (Galafassi, Gluz, \& Galafassi, 2013). A análise, de cunho quantitativo e qualitativo, levou em conta as dimensões técnicas e pedagógicas dos objetos de aprendizagem e dos ambientes virtuais. No que diz respeito aos ambientes virtuais de aprendizagem, o estudo mostrou que pesquisas nessa área estão em franco crescimento, além de apresentarem maturidade técnica (Galafassi et al., 
2013) em relação às atuais ferramentas e plataformas utilizadas. A abordagem de discussões sobre ambientes virtuais também se faz muito presente nos eventos. No caso do ENEQ 2010, observamos o trabalho sobre " $\mathrm{O}$ uso de ambiente virtual de aprendizagem como apoio ao ensino presencial de Ciências em proposta interdisciplinar pela utilização do filme o Óleo de Lorenzo como contexto” (Costa, Nascimento, Oliveira, \& Rocha, 2010). Nele é debatida a utilização de um ambiente virtual de aprendizagem em apoio ao ensino presencial com o objetivo de permitir ao aluno ser observador de sua aprendizagem, possibilitando a formação autônoma e a compreensão das relações entre os fenômenos que ocorrem no microuniverso das células e o funcionamento do corpo, bem como possibilitando o estudo de compostos orgânicos importantes no metabolismo. A atividade interdisciplinar é realizada por meio do uso do filme "o óleo de Lorenzo" com atividades via Internet na plataforma MOODLE e presenciais em sala de aula. Os resultados destacam uma apreensão do conhecimento químico e biológico como sendo um só e a melhoria dos componentes curriculares, com o uso das vantagens da Internet com a mediação do professor.

Na revista eLearning Papers, encontramos discussões sobre as redes sociais no ensino, em que Carbó e Antolí (2011) identificam distintos processos de aprendizagem informal que ocorreram durante um curso, quando os participantes estabeleceram contatos e intercâmbios fora da sala de aula. O estudo discute a percepção dos estudantes sobre o que tem aprendido através das ferramentas da Web 2.0. O Facebook foi uma das redes sociais mais estudadas nos eventos analisados. No ENEQ de 2014 a análise das interações ocorridas nesse ambiente destaca o posicionamento dos estudantes e como se dá a circulação de ideias no espaço virtual do Facebook (Silva, Lima, \& Machado, 2014). A partir de uma piada em um grupo, foram analisados os enunciados por meio do conceito de carnaval elaborado por Bakhtin. Os resultados encontrados, segundo os autores, indicaram a carnavalização do Facebook e da sala de aula quando, a partir de uma piada, discute-se a Química na rede social.

Na Tabela 8 descrevemos os trabalhos publicados nos periódicos e congressos analisados em três categorias: análises das ferramentas; aplicações e uso das ferramentas; e perspectivas (discussões teóricas sobre as ferramentas da Web 2.0).

Tabela 8: Categorias abordadas nas publicações envolvendo ferramentas da Web 2.0.

\begin{tabular}{cccc}
\hline Publicação & Análise & Aplicação & Perspectiva \\
\hline QNEsC & 1 & 2 & 0 \\
\hline EC & 0 & 2 & 0 \\
\hline RBIE & 11 & 19 & 7 \\
\hline ELearn. & 38 & 23 & 19 \\
\hline ENEQ & 15 & 28 & 3 \\
\hline RIBIE & 22 & 16 & 14 \\
\hline TISE & 37 & 36 & 12 \\
\hline IE & 13 & 12 & 9 \\
\hline Total & $\mathbf{1 3 7}$ & $\mathbf{1 3 8}$ & $\mathbf{6 4}$
\end{tabular}

Os resultados indicam que, durante o primeiro decênio da Web 2.0, ocorreu um equilíbrio de publicações envolvendo a análise das ferramentas da Web 2.0 e sua aplicação. Esses dados refletem a possível tendência de pesquisadores investigarem sobre a Web 2.0, a fim de conhecer e compreender seus recursos e posteriormente aplicá-los no âmbito educacional (Ferreira, 2002; Isotani et al., 2009; Leite, 2015). É importante destacar que, na Web 2.0, professores e alunos se tornam prosumidores (Leite \& Leão, 2015), isto é, produtores e consumidores de conteúdo na web, e participam ativamente na avaliação do conteúdo, no desenvolvimento de habilidades e na construção do conhecimento de forma coletiva.

Algumas tendências também são observadas nos artigos/comunicações analisados nesta pesquisa. Observamos, por exemplo, que o wiki, uma das ferramentas mais utilizadas na Web 2.0, 
tem seu uso escasso nas práticas pedagógicas dos professores. O grande diferencial do wiki em relação a uma página na Internet é que ele possibilita criar conteúdo de forma colaborativa, armazenando o histórico de todas as mudanças realizadas na página, desde sua primeira publicação (Isotani et al., 2009). Nos trabalhos analisados ressaltamos que este recurso é pouco explorado no Ensino de Química, o que amplia as possibilidades para o desenvolvimento de atividades por professores em suas práticas pedagógicas. É importante destacar que existem diversos wikis sobre conteúdos de química, porém muitos destes não são acompanhados pelos educadores, fornecendo informações errôneas sobre os conceitos químicos (Leite, 2015). Ao ignorar o uso de wikis, o professor se distancia das possibilidades em se trabalhar com os alunos de forma colaborativa e na partilha do conhecimento (Vieira, 2009).

Por outro lado, nota-se que, em relação às redes sociais, há uma tendência de pesquisas envolvendo o Facebook (Raupp \& Eichler, 2012; Silva et al., 2014). São inúmeras as possibilidades de utilização desta rede social na educação. Por exemplo, as publicações dos professores e alunos neste ambiente deixam de estar limitadas somente ao espaço físico da sala de aula e passam a possibilitar interações híbridas, de todos e para todos, em qualquer lugar do mundo. Além do Facebook, destacamos o Youtube que tem apresentado grande crescimento nas produções envolvendo o Ensino de Química. O Youtube, uma rede social de compartilhamento de vídeos, tem ofertado à comunidade de educadores a possibilidade de consultarem e divulgarem conteúdos multimídias (vídeos, fotos, sons, etc.) para a comunidade acadêmica. Ao receber o conteúdo, a comunidade pode avaliá-lo, fazer comentários (tanto para o criador como para outros usuários), ou propor formas de melhorar o conteúdo (Isotani et al., 2009). A explosão das redes sociais, onde compartilhamos informação e conhecimento, promove uma nova tendência na criação de uma inteligência comum e coletiva, criada por e para os prosumidores. O Youtube, a Wikipédia e o Google+ são ferramentas da Web 2.0 que têm se destacado no ambiente escolar, sendo a segunda, terceira e quarta ferramentas mais utilizadas pelos alunos (Oliveira \& Dutra, 2014). A desmistificação do professor como o "único detentor do conhecimento" pode promover uma aprendizagem colaborativa tão desejada por diversas correntes da pedagogia virtual e deve ser aproveitada e levada em conta para os novos modelos e métodos de educação virtual.

As ferramentas da Web 2.0 promovem a participação ativa de alunos e professores para produzir/avaliar o conteúdo e desenvolver habilidades e conhecimento de forma coletiva. É necessário identificar e explicitar as produções envolvendo esses recursos e considerar que seus potenciais resultados podem modificar a forma como interagimos e aprendemos em ambientes baseados na Web.

Por fim, elencamos cinco tendências/desafios que podem ser oriundas do uso das ferramentas da Web 2.0 no Ensino de Química:

1) Possibilidade de aulas mais descentralizadas - baseadas no ensino híbrido (Bacich, Neto, \& Trevisani, 2015; Leite, 2017);

2) Atividades promovendo uma aprendizagem colaborativa ao invés de individualista (Linhares \& Chagas, 2015; Silva Filha, Silva, \& Freitas, 2016; Torres, Alcantara, \& Irala, 2004);

3) Aprendizagem ocorrendo na rede - baseado nos princípios do conectivismo (Linhares \& Chagas, 2015; Siemens, 2004);

4) Estratégias envolvendo aprendizagem tangencial (Leite, 2016; Portnow \& Floyd, 2008) como forma de introduzir e/ou discutir conceitos científicos;

5) Estratégias didáticas baseadas na aprendizagem móvel (Leite, 2014; Nichele \& Schlemmer, 2014).

Previsões são sempre arriscadas no universo movediço das sociedades líquidas (Bauman, 2013) em que estamos imersos. A nossa premissa é que as ferramentas da Web 2.0 vieram para 
permanecer, crescer e se multiplicar, pois as tecnologias (isto é, a Web 2.0), assim como a vida, estão em contínuo crescimento.

\section{Considerações finais}

O uso das tecnologias interativas na educação, independentemente de sua modalidade, é hoje tão necessário quanto foram a lousa e o giz em tempos passados. Assim, o presente estudo analisou o estado da arte da produção acadêmica de periódicos e congressos científicos sobre as ferramentas da Web Social. Esta investigação analisou 6061 artigos/comunicações, das quais pouco mais de 5\% são sobre ferramentas da Web 2.0 no Ensino de Química. Apesar do total de publicações nas revistas e congressos analisados, é válido lembrar que o número de pesquisas voltadas para o uso das ferramentas da Web 2.0, no Ensino de Química, necessita de ampliação.

O estudo aqui apresentado realça a dispersão de pesquisas envolvendo a Web 2.0 no Ensino de Química na amostra analisada, o que pode ajudar a compreender por que razão ainda não existe no ensino de ciências um corpo de conhecimentos específico e coerente que ligue as várias peças fragmentadas de conhecimento. Entretanto, é possível observar artigos/comunicações bem estabelecidos no que se refere à Web 2.0 no ensino e que refletem a maturidade da área de pesquisa, bem como estudos emergentes. Ademais, este trabalho assume importância na medida em que investiga pesquisas relativas às ferramentas da Web 2.0 no ensino, em especial de Química, e permite um acompanhamento das publicações, autores/pesquisadores e temáticas estudadas, bem como a identificação de possibilidades de novas pesquisas. Ao analisar os artigos/comunicações na web, observamos que todos os trabalhos publicados são de livre acesso; contudo, foi uma tarefa complexa construir uma visão geral dos temas mais abordados em cada uma das fontes consultadas. Nesse sentido, no conjunto dos artigos/comunicações analisados, em todos os tipos de orientação da pesquisa, evidenciamos que os temas "ambientes virtuais" e "blogs" foram os que se destacaram na temporalidade de dez anos de pesquisa, representando $25 \%$ e $11 \%$ do total de publicações/comunicações sobre TIC no Ensino de Química, respectivamente.

Um aspecto digno de referência é as tendências observadas neste levantamento e revisão do conhecimento produzido sobre o tema, sendo um passo indispensável para desencadear um processo de análise qualitativa dos estudos produzidos nas diferentes áreas do conhecimento.

Os resultados dessa investigação poderão servir de base para a ampliação das pesquisas na área e/ou para o desenvolvimento de novos estudos. Entendemos, como fator limitador desta pesquisa, a quantidade de periódicos e de congressos analisados. Porém, para que se propôs a fazer, este estudo suscitou e respondeu a contento a sua questão de pesquisa. Também é desejável continuar a tentar obter uma melhor compreensão das características e evolução da Web 2.0 no Ensino de Química, tendo em conta a ênfase que lhe é agora dada pelos pesquisadores. Destarte, sugerimos, para futuras pesquisas, uma análise mais ampla de revistas e eventos científicos e, posteriormente, uma análise das publicações.

Cabe ressaltar que a incorporação da Web 2.0 (em aulas futuras ou imediatamente) possibilita que professores e alunos se concentrem mais nos processos importantes de aprendizagem - que consistem na interpretação e organização da informação - que na mera aquisição de dados. Os educadores poderiam desempenhar de modo mais ativo o papel de facilitadores. Pensando neste aspecto para que as Tecnologias da Informação e Comunicação, neste momento a Web 2.0, não sejam vistas como apenas mais um modismo, mas com a relevância e o poder educacional transformador que possuem, é preciso que se reflita sobre o processo de ensino de maneira global. 
Fica o desafio de uma profunda e continuada reflexão da comunidade de pesquisadores em ensino de ciências, em especial no Ensino de Química, para acompanhar a evolução da Web 2.0 na prática docente e como é inserida nos processos de ensino e aprendizagem, tendo em vista "saber onde estamos" e formular prioridades de pesquisa a médio prazo.

\section{Agradecimento}

Ao CNPq pela bolsa concedida para a realização da pesquisa.

\section{Referências}

Azevedo, A. W., \& Almeida, P. E. de. (2011). Biblioteca 2.0: Uso das ferramentas Web 2.0 na biblioteca INATEL. In XXIV Congresso Brasileiro de Biblioteconomia, Documentação e Ciência da Informação. [GS Search]

Bacich, L., Neto, A. T., \& Trevisani, F. de M. (2015). Ensino híbrido: personalização e tecnologia na educação. Porto Alegre: Penso. [GS Search]

Barro, M. R., Baffa, A., \& Queiroz, S. L. (2013). Blogs na formação inicial de professores de química. Química Nova Na Escola, 35(4), 283-291. [GS Search]

Bauman, Z. (2013). Liquid modernity. John Wiley \& Sons. [GS Search]

Borba, J. A., Poeta, F. Z., \& Vicente, E. F. R. (2011). Teoria da Contabilidade: uma Análise da Disciplina nos Programas de Mestrado Brasileiros. Sociedade, Contabilidade E Gestão, 6(2), 124-138. [GS Search]

Brito, J. L., \& Silva, P. M. (2010). Ferramentas da web 2.0 em bibliotecas universitárias: um estudo de caso. Biblionline, esp., 23-33. [GS Search]

Brownstein, E., \& Klein, R. (2006). Blogs: Applications in science education. Journal of College Science Teaching, 35(6), 18-22. [GS Search]

Caldeira, M. L., Silva, M. F. da, \& Magdalena, M. C. (2015). Blogs na área de educação: inovação, conhecimento e aprendizagem. In Taller Internacional de Software Educativo (TISE) (pp. 627-632). [GS Search]

Carbó, A. R., \& Antolí, N. S. (2011). Online students initiate informal learning practices using social tools. eLearning Papers, 26, 1-4. [GS Search]

Clercq, L. De. (2009). ¿Qué es la web 2.0? In M. Grané \& C. Willem (Eds.), Web 2.0: Nuevas formas de aprender y participar (pp. 21-32). Barcelona: Laertes Educación. [GS Search]

Costa, W. L. de L., Nascimento, G. G. do, Oliveira, E. S. B. de, \& Rocha, D. A. da. (2010). O uso de ambiente virtual de aprendizagem como apoio ao ensino presencial de Ciências em proposta interdisciplinar pela utilização do filme o Óleo de Lorenzo como contexto. In $X V$ Encontro Nacional de Ensino de Química (pp. 1-12). Retrieved from http://www.sbq.org.br/eneq/xv/resumos/R0953-1.pdf

Dias, W. de O., Neto, J. E. B., \& Cunha, J. V. A. da. (2011). A comunicação do conhecimento científico: dados sobre a celeridade do processo de avaliação e de publicação de artigos científicos em periódicos da área de contabilidade. Revista Contemporânea de Contabilidade, 8(15), 41-62. [GS Search]

Ferreira, N. S. de A. (2002). As pesquisas denominadas “estado da arte.” Educação \& Sociedade, 23(79), 257-272. [GS Search] 
Galafassi, F. P., Gluz, J. C., \& Galafassi, C. (2013). Análise crítica das pesquisas recentes sobre as tecnologias de objetos de aprendizagem e ambientes virtuais de aprendizagem. Revista Brasileira de Informática Na Educação, 21(3), 41-52. [GS Search] doi: 10.5753/rbie.2013.21.03.100

Isotani, S., Mizoguchi, R., Bittencourt, I. I., \& Costa, E. (2009). Estado da arte em web semântica e web 2.0: potencialidades e tendências da nova geração de ambientes de ensino na internet. Revista Brasileira de Informática na Educação, 17(1), 30-42. [GS Search] doi: $\underline{10.5753 / \text { rbie.2009.17.01.30 }}$

Leão, M. B. C. (2011). Tecnologias na educação: uma abordagem crítica para uma atualização prática. Recife: UFRPE. [GS Search]

Leite, B. S. (2014). M-Learning: o uso de dispositivos móveis como ferramenta didática no Ensino de Química. Revista Brasileira de Informática na Educação, 22(3), 55-68. [GS Search] doi: 10.5753/rbie.2014.22.03.55

Leite, B. S. (2015). Tecnologias no ensino de química: teoria e prática na formação docente (1st ed.). Curitiba: Appris. [GS Search]

Leite, B. S. (2016). Aprendizagem tangencial no processo de ensino e aprendizagem de conceitos científicos: um estudo de caso. RENOTE. Revista Novas Tecnologias Na Educação, 14(2), 1-10. [GS Search] doi: $10.22456 / 1679-1916.70678$

Leite, B. S. (2017). Ensino híbrido utilizando a Rede Social Edmodo: um estudo exploratório sobre as potencialidades educacionais para o Ensino de Química. Revista Brasileira de Ensino de Ciência e Tecnologia, 10(3), 206-230. doi: 10.3895/rbect.v10n3.4873

Leite, B. S., \& Leão, M. B. C. (2015). Contribuição da Web 2.0 como ferramenta de aprendizagem: um estudo de caso. Revista Brasileira de Ensino de Ciência e Tecnologia, 8(4), 288-315. [GS Search] doi: 10.3895/rbect.v8n4.2790

Linhares, R. N., \& Chagas, A. M. (2015). Conectivismo e aprendizagem colaborativa em rede: 0 facebook no ensino superior. Revista Lusófona de Educação, 29(29), 71-87. [GS Search]

Ludke, M., \& André, M. E. D. A. (2012). Pesquisa em Educação: Abordagens qualitativas. São Paulo: E.P.U.

Marques, C. T. (2004). Potencialidades e limitações da aplicação simultânea de aromas e de pigmentos sensíveis ao calor e à luz em artigos de moda praia. Universidade do Minho. [GS Search]

Martinhão, M. S. (Ed.). (2016). Pesquisa sobre o uso das tecnologias de informação e comunicação nas escolas brasileiras: TIC educação 2015. São Paulo: Comitê Gestor da Internet no Brasil. [GS Search]

Meli, D. B., \& Oliveira Neto, J. D. de. (2011). O perfil da colaboração nos periódicos contábeis nacionais: muitos one-timers e poucos continuants. Revista Contemporânea de Contabilidade, 8(15), 151-176. [GS Search] doi: 10.5007/2175-8069.2011v8n15p151

Mello, S. F. M. (2010). Comunicação e organizações na sociedade em rede: novas tensões, mediações e paradigmas. 2010. Tese de Doutorado. Universidade de São Paulo. [GS Search]

Moraes, R. (1999). Análise de conteúdo. Revista Educação, Porto Alegre, 22(37), 7-32. [GS Search]

Neubert, P. da S., Rodrigues, R. S., \& Fachin, G. R. (2016). Uso de ferramentas Web 2.0 pelos periódicos ibero-americanos indexados no Web of Science e Scopus. Transinformação, 28(2), 127-141. [GS Search] doi: 10.1590/2318-08892016000200001 
Nichele, A. G., \& Schlemmer, E. (2014). Aplicativos para o ensino e aprendizagem de Química. RENOTE, 12(2). [GS Search] doi: 10.22456/1679-1916.53497

O’Reilly, T. (2005). What Is Web 2.0: Design Patterns and Business Models for the Next Generation of Software. [GS Search]

Oliveira, E. B. de, \& Dutra, M. L. (2014). Um levantamento sobre do uso de ferramentas da Web 2.0 entre os estudantes da Ciência da Informação da Universidade Federal de Santa Catarina. Encontros Bibli: Revista Eletrônica de Biblioteconomia E Ciência Da Informação, 19(39), 153-182. [GS Search] doi: 10.5007/1518-2924.2014v19n39p153

Portnow, J., \& Floyd, D. (2008). The power of tangential learning. Edge Online. [GS Search]

Posada, J. E. G., Buchdid, S. B., \& Baranauskas, M. C. C. (2016). A informática na educação: o que revelam os trabalhos publicados no Brasil. Revista Brasileira de Informática $\mathrm{Na}$ Educação, 24(1), 141-155. [GS Search] doi: 10.5753/rbie.2016.24.1.142

Raupp, D., \& Eichler, M. L. (2012). A rede social Facebook e suas aplicações no ensino de química. RENOTE, 10(1). [GS Search] doi: 10.22456/1679-1916.30860

Ribeiro, H. C. M. (2015). Estado da arte da Revista Contabilidade Vista \& Revista: uma análise da produção acadêmica de 2008 a 2012. ConTexto, 15(30), 36-56. [GS Search]

Sadaf, A., Newby, T. J., \& Ertmer, P. A. (2016). An investigation of the factors that influence preservice teachers' intentions and integration of Web 2.0 tools. Educational Technology Research and Development, 64(1), 37-64. [GS Search] doi: 10.1007/s11423-015-9410-9

Siemens, G. (2004). Conectivismo: uma teoria de aprendizagem para a idade digital. Trad. Bruno Leite. [GS Search]

Silva, G. R. da, Lima, M. E. C. de C., \& Machado, A. H. (2014). Redes sociais e o ensino de química: a carnavalização, o riso e a circularidade no Facebook. In XVII Encontro Nacional de Ensino de Química (pp. 5179-5190).

Silva Filha, R. T. da, Silva, A. A. da, \& Freitas, S. R. S. (2016). Uma alternativa didática às aulas tradicionais de ciências: aprendizagem colaborativa e modelização aplicadas ao ensino do sistema urinário. Cadernos de Educação, 15(31), 87-105. [GS Search] doi: 10.15603/16798104/ce.v15n31p87-105

Torres, P. L., Alcantara, P. R., \& Irala, E. A. F. (2004). Grupos de consenso: uma proposta de aprendizagem colaborativa para o processo de ensino-aprendizagem. Revista Diálogo Educacional, 4(13), 129-145. [GS Search]

Vieira, M. F. V. (2009). Ambiente Wiki na educação: produção colaborativa do conhecimento compartilhado na web. Revista Tecnologias Na Educação, 1. [GS Search] 